University of Nebraska - Lincoln

DigitalCommons@University of Nebraska - Lincoln

Space, Cyber, and Telecommunications Law

Program Faculty Publications

Law, College of

2011

\title{
Space for Celestial Symphonies? Towards the Establishment of International Radio Quiet Zones
}

Frans G. von der Dunk

University of Nebraska - Lincoln, fvonderdunk2@unl.edu

Follow this and additional works at: https://digitalcommons.unl.edu/spacelaw

Part of the Air and Space Law Commons

von der Dunk, Frans G., "Space for Celestial Symphonies? Towards the Establishment of International Radio Quiet Zones" (2011). Space, Cyber, and Telecommunications Law Program Faculty Publications. 59. https://digitalcommons.unl.edu/spacelaw/59

This Article is brought to you for free and open access by the Law, College of at DigitalCommons@University of Nebraska - Lincoln. It has been accepted for inclusion in Space, Cyber, and Telecommunications Law Program Faculty Publications by an authorized administrator of DigitalCommons@University of Nebraska - Lincoln. 


\title{
Space for Celestial Symphonies? Towards the Establishment of International Radio Quiet Zones*
}

\author{
Frans G. von der Dunk \\ International Institute of Air and Space Law, Leiden University, Leiden, The Netherlands (affiliation 2012: \\ College of Law, University of Nebraska-Lincoln, Lincoln, Nebraska, USA; fvonderdunk2@unl.edu)
}

\section{Abstract}

The growth of low- and medium-Earth orbit mobile satellite communications poses a threat to radio astronomers which could be mitigated by the establishment of international radio quiet zones (IRQZs), where communications traffic is managed (not eliminated) to allow radio astronomy to continue. Using the prototype of national such zones in the USA, this article explains how the system would work and discusses the international legal parameters that would bound it, drawing on current aerospace, outer space and high seas legislation. Precedents for an IRQZ_Exclusive Economic Zones, denuclearized zones and the Antarctic regime-are also examined.

\section{Introduction}

In everyday life, it is increasingly accepted that the general benefits to society provided by mobile communications, large as they may be, do not necessarily justify the uninhibited use of mobile phones everywhere at every moment. This is rather obvious when prominent safety or security considerations are at stake, for instance, whilst aircraft are in the process of taking off or landing, or during police or emergency service operations. But also in concert halls, opera houses and theatres around the world the use of such devices is increasingly being frowned upon, discouraged or even positively prohibited. The interests of visitors at large in enjoying symphonies and operas thus take precedence over the interest of any particular visitor in being able to communicate by phone everywhere at all times.

A similar balance might now be called for at another level. In spite of severe setbacks, the progressive development of the so-called 'LEO-systems' and 'MEO-systems' for commercial mobile satellite communications is undeniable_-and poses a direct threat to radio astronomy and scientific exploration of outer space around the world. These activities, just like concert attendance amount to listening (in this case to celestial sym-

*Published with kind permission of the OECD Megascience Forum. The present author contributed to the discussion on International Radio Quiet Zones by writing a report upon invitation by the OECD Megascience Forum. This report was also used as the basis for the current article. phonies_-radio signals from stars, black holes and the like); not showing immediate economic benefit (or, perhaps more appropriately, not showing benefits predominantly of an economic nature) but nevertheless requiring some 'space.'

In the past, the interests of radio astronomy were given due attention through formal protection by the International Telecommunication Union (ITU) of certain frequency bands, where radio astronomers were granted exclusive or priority usage. Also, many observatories were located in thinly populated areas where other usage of the radio spectrum was not particularly prominent. Finally, the relatively low number and almost exclusively governmental character of telecommunications players world-wide was a factor generally conducive to allowing radio astronomy, as a scientific activity in the public interest, its proper place alongside other uses of the radio spectrum.

Fears are, however, that soon no place on earth will remain free from coverage by communication signals; there would then be no more geographic 'safe havens' for radio astronomy. Also, the power of the satellite transponders involved is of such magnitude that spillover to adjacent frequency bands will grow enormously - at a time radio astronomy is increasingly confronted with the need to 'listen' on frequencies across the entire radio spectrum. Radio astronomers are passivelisteners, not able to determine or change the frequencies of cosmic events taking place elsewhere in the universe, but because of the foregoing even allocation of frequency bands on an exclusive or primary basis might no longer suffice to provide radio 
astronomers with useful 'windows' to 'listen'. Finally, the moral authority and legal effectiveness of ITU in balancing the various interests is increasingly being challenged both in law and in practice.

The comparison, in particular, with concert attendance thus offers itself again. When it is possible to effectuate an approach of limited but conscious abstention on such a 'microlevel' by a combination of rules and decency, it should perhaps be possible to effectuate it on a 'macro-level' as well. The scientific activities of radio astronomers are of substantial interest to mankind, and scientific exploration has repeatedly been recognized as one of the major human activities vis-à-vis outer space which need and deserve - and to some extent already enjoy-protection by law. ${ }^{1}$ There should continue to be at least some 'space for celestial symphonies', and it is the aim of the present article to analyse in what way the law could help to achieve such a goal.

\section{IRQZs: National Precedents in the US}

Of course, radio astronomers have noted the aforementioned developments with considerable concern. Thus, for example, the OECD Megascience Forum, established a few years ago by a number of governments substantially funding scientific research on the universe, is giving particular expression to this concern. ${ }^{2}$ The Megascience Forum has focussed on finding solutions essentially along three lines.

First, development of innovative technology is pursued, as the separation or filtering of man-made signals from those of interest to radio astronomy would obviously assist in preserving research opportunities for radio astronomers. Second, forward-looking regulatory approaches are being investigated. Radio astronomy does not need permanent exclusivity, it is understood: in a number of cases it would be possible to devise means of sharing certain frequency bands on a temporal basis.

${ }^{1}$ Cf. e.g. Preamble; Artt. I, III, IX, Treaty on Principles Governing the Activities of States in the Exploration and Use of Outer Space, including the Moon and Other Celestial Bodies (hereafter Outer Space Treaty), London/Moscow/Washington, adopted December 19, 1966, opened for signature January 27, 1967, entered into force October 10, 1967; 6 ILM 386 (1967); 18 UST 2410; TIAS 6347; 610 UNTS 205.

${ }^{2}$ Reference may especially be had to "Protecting the Future of Radio Astronomy," Report prepared by the Megascience Forum's Working Group on Radio Astronomy, November 1998, and the annexes thereto, which provide for an extensive evaluation of this problem which the present article can merely summarize. Some of the issues raised in the present article continue to be extensively discussed in the context of the Megascience Forum and other related fora.
The third option, to be considered in detail here, is the most revolutionary one as well as being most interesting from a legal perspective. It concerns the establishment of 'international radio quiet zones' (IRQZs) — the designation of areas on earth where satellite-related telecommunication signals are kept at or below levels tolerable for radio astronomy observations.

The idea of a 'radio quiet zone' is not as outrageous as it may sound (in particular to satellite communication operators). Interesting precedents are provided in the case of the US, where already in 1958 a first National Radio Quiet Zone (NRQZ) was established to protect research activities at the National Radio Astronomy Observatory (NRAO) at Green Bank and the Naval Radio Research Laboratory (NRL) at nearby Sugar Grove. ${ }^{3}$ This NRQZ comprises a square zone of some $34,000 \mathrm{~km}^{2}$ in the states of West Virginia and Virginia. In this zone, new applicants for telecommunications licenses-i.e. prospective operators of radio transmitters-were henceforth subjected to special procedures before the Federal Communications Commission (FCC). Among others, the House of Representatives of West Virginia passed a Bill on August 9, 1956 whereby it further elaborated some legal consequences of the establishment of this NRQZ, largely on West Virginian territory, by the federal authorities.

With a few exceptions, such new applicants would have to notify the NRAO and NRL in due time of their intended operations with radio transmitters, providing them with all relevant technical and operational details. These institutions are thereby given the opportunity to comment on the proposed activity and the possibilities of interference with their research activities. Acting upon such recommendations, the FCC decides whether to grant a particular license, depending both upon the efforts of the applicant to accommodate the wishes of NRAO and/or NRL in terms of preventing unacceptable interference, and upon the reasonableness of the particular balance struck in any individual case between the interests of radio astronomy and those of economic and commercial activities.

For the purpose of legal certainty and predictability, and of allowing prospective applicants the opportunity to accommodate ex ante the relevant obligations imposed, complicated schemes were developed as to the various allowable power densities of proposed transmitters, depending inter alia upon

${ }^{3}$ FCC Notice of Proposed Rule Making of June 20, 1956, Docket No. 11745, appearing in the Federal Register on June 27, 1956 (21FR4680); Further Notice of Proposed Rule Making of June 5, 1958, Docket No. 11745, published in the Federal Register on June 11, 1958 (23FR4103), finally adopted November 19, 1958. See further J.L. Dolan, Spectrum Control Procedures for the National Radio Astronomy Observatory, 61 Proceedings of the Institute of Electrical and Electronics Engineers (1973), 1,350-1,352, for more details. 
distance and frequency. In the West Virginian Bill-officially named "Radio Astronomy Zoning Act"-furthermore, for every particular distance up to 10 miles from the NRAO admissible levels of instantaneous peak field strength were provided in a quite detailed fashion-for any equipment. In addition, a mobile surveillance system was built at NRAO to monitor interference for the purpose of upholding the limits thus imposed.

This example has been followed by others in the US, since the concept of the NRQZ was seen to fulfill its purposes satisfactorily at least from the perspective of the FCC and the radio astronomy community. In 1997, a Radio Astronomy Coordination Zone was established along the same lines in Puerto Rico, covering the whole island as well as a few small neighboring islands. ${ }^{4}$ The observatory at Arecibo (on Puerto Rico) had previously been protected by a four-mile Protection Zone, but this protection was no longer considered sufficient in the light of increasing usage of radio frequencies and increasing power levels involved. The Radio Astronomy Coordination Zone thus considerably enlarged the relevant area, depending upon particulars to either 10 miles or the whole island and its small neighbors.

\section{From National to IRQZs}

The establishment of these national zones is of great interest as a useful precursor to the possible establishment of IRQZs. Nevertheless, a number of aspects would require further consideration when moving from the NRQZ precedents to the IRQZs to be established.

First, it has to be emphasised that NRQZs provide for radio quiet zones, not radio silent zones. No absolute and comprehensive ban on mobile communications is envisaged - rather, 'interference-or-not' is the issue, reflected in elaboration and imposition of permissible power levels. There are a considerable number of exceptions, moreover: for example, in 1973, there were some 1,500 licensed transmitters operating in the Green Bank NRQZ, in spite of its character as a rather rural area. Most of those transmitters concerned police and emergencyusage-related equipment. Such exceptions are obviously reasonable and even inevitable, and for any IRQZ a similar list of exceptions will (have to) apply to such clearly public uses regarding safety and security.

Absolute radio silence in an IRQZ would therefore not be feasible-nor would it be necessary. The essential feature of an IRQZ would be the link between the 'spatialist' parameter (the measurements in kilometers or miles of distance from

${ }^{4}$ FCC Notice of Proposed Rule Making, ET Docket No. 96-2, 11 FCC Rcd 1716 (1996); adopted as RM-8165, September 26, 1997, FCC 97-347. the observatory to be protected) and the 'functionalist' parameter (the maximum level of power which would still be acceptable at such distance, because of not causing intolerable interference). Furthermore, radio astronomy's interests would not necessarily call for reservation of the whole frequency spectrum; neither do they require radio quietness $24 \mathrm{~h}$ per day, 7 days per week. Details, however, would still have to be worked out: what periods of radio quietness at which frequencies would have preference over which others?

Second, the relevant legislation in NRQZs Is-for obvious, largely historical and practical reasons-mostly targeted at fixed terrestrial transmitters. Such transmitters are, both for their size and for their fixation, relatively easily detected, and their activities consequently relatively easily monitored. Furthermore, these transmitters evidently and comprehensively fall under the sovereign control of a single state. The major problem for any IRQZ, by contrast, lies in the involvement of mobile handsets of often small size, for a major part moving in and out of any particular area (this, moreover, also across international borders), respectively of satellites moving rapidly many kilometers overhead. Whereas an NRQZ could, for all practical purposes, be constituted as a two-dimensional zone with a relatively simple monitoring structure, in view of the crucial involvement of satellite sources any IRQZ would need to have a fundamentally three-dimensional character, requiring a more complex and extended monitoring regime.

A series of superimposing virtual domes could be visualized, one dome with particular geographical measurements for every particular power level acceptable at the distance of such measurements, and each dome with the observatory at its geometrical center. The correlation between the measurements of any particular dome and the maximum power level it represents - in other words at what distance which power level is still acceptable from the point of view of the observatory at issue-is a matter for the various stakeholders (including radio astronomers) to determine jointly.

Of course, the dome is merely a theoretical picture, not taking into account practical features either of the area under consideration (mountainous? covered with forests?), or of technical differences (what may be an acceptable power level at one frequency or for one type of applications may not be so for others), or of other relevant details. Again, it would be for the stakeholders to establish a clear picture of what is a maximum tolerable level of interference at each particular turn.

Third, the established NRQZs are of a rather small size anyhow: the West Virginian Bill implementing the Green Bank IRQZ refers to prohibited power levels at distances of up to 10 miles from the NRAO only. By comparison, in satellite mobile communications much higher power levels are at issue, and one would therefore probably require transmitters operating hundreds or even thousands of miles from the obser- 
vatory-as mentioned, in three dimensions! - to fall within the applicable limitations, at least to the extent that their radio emissions would interfere substantially with the activities concerned. Of course, the likelihood of international ramifications increases correspondingly for an IRQZ.

Fourth, in the case of NRQZs, the US FCC has the final say as to whether a license will be granted-that is, whether appreciable interference will actually occur or not. Here, one touches upon the rather comprehensive scope of applicable enforcement competencies involved in NRQZs. Within the US, the FCC is a federal government body, operating under federal laws and itself endowed with comprehensive regulatory competencies. Licenses for radio communications activities are used as the mechanism to protect radio astronomy; by not granting them or by subjecting them to applicable conditions, substance is given to the protection of radio astronomy in the relevant cases. These licenses do not just deal with particular frequencies to be used on an exclusive or preferential basis, they also incorporate the 'spatial' aspects of the protection regime: the area where certain equipment is allowed to operate under relevant conditions and which is consequently to be monitored. Most importantly, any violation of license obligations can be brought before US courts to be adjudicated and, if necessary, enforced in that area.

It remains to be seen how these aspects of NRQZs would translate to cases of IRQZs, in view of the international ramifications, large complexity and measure of detail of arrangements required for a full-fledged and effective IRQZ. Expeditious handling of all relevant requests for licenses or permissions from communication operators in the IRQZ, respectively for exceptions to the established maxima, would require a substantial and continuous effort in terms of manpower and finances. Also, a mechanism should be provided which determines whether any established maximum has been exceeded. It should be the interference measured by such mechanism at the observatory in question which in the end determines the constellation of domes, yet at the same time it should be translated into output levels of relevant equipment in order to provide for a workable determination of that constellation through the virtual series of superimposing domes. This translation again is a matter in the first place for stakeholders to achieve and effectuate. Precisely because an IRQZ would require such efforts on a much larger scale, in view of the size and international ramifications, however, the international (institutional) situation in its current configuration would be much less conducive to accommodate these needs.

\section{The International Legal Parameters for IRQZs}

The geographical area required for an IRQZ - as the most outward dome deemed necessary-would easily measure some thousands of kilometers, in three dimensions, if it is to achieve the desired effect. (In the case of the geostationary orbit, transmissions even from close to $36,000 \mathrm{~km}$ are supposed to be received clearly on earth. ${ }^{5}$ ) This results in a fundamental twofold legal approach when it comes to the international legal framework for IRQZs, which translates into two distinct geographical parts of any individual IRQZ: national territory, including airspace, respectively the international areas of outer space and (occasionally) the high seas.

\subsection{National Territory and National Airspace}

The area under consideration would find itself for one part within the territory of a particular state, or possibly involve the territory of a small number of states. This also applies in the case of observatories on islands in the high seas. Finding one or a few states willing to implement the measures desired would suffice here. ${ }^{6}$

Basically, any particular state or group of neighboring states would have complete freedom to establish legislation prohibiting or conditioning any relevant activity as far as desired, and thus, e.g. to establish radio quietness (or even silence) in a particular area. Both legal instruments and (if necessary) relevant precedents of different sorts will be available, probably in abundance, to implement within the territory/ies concerned the required national measures. Individual states also have the comprehensive means to monitor, adjudicate and if necessary sanction potentially interfering activities within the designated area. The size of the required area, at least 'horizontally', presents no additional problems from this perspective; what counts is which state's territory would be included in the zone to be designated.

\footnotetext{
${ }^{5}$ Note that, for practicability's sake, international radio quiet zones should not be situated near the equator. The geostationary orbit finds itself perpendicularly above the equator and contains satellites which by definition hardly move relative to earth. This means that such satellites would, to the extent already present, have to be largely quieted, completely silenced or even removed from that orbit, and to the extent planned, prohibited or redirected to other slots on or other orbits. In view of the advantages of using this orbit and its consequent popularity, it would neither be realistically feasible nor provide a justifiable balance between commercial and scientific interests, to establish IRQZs on or near the equator.

${ }^{6}$ Several areas have already been seriously discussed from this perspective, the essence being that such areas have no big cities and are generally rather thinly populated and travelled. This means that the 'sacrifice' of severely curtailing mobile satellite communication activities for the purpose of radio astronomy would be relatively small.
} 
This includes, legally speaking, the airspace over that territory/those territories. States at the outset have full legal control over which aircraft enter their airspace, and under which conditions. Among such conditions could rank, at least in principle, circumvention of any part of the national airspace which is included in an IRQZ. ${ }^{7}$ It should be pointed out that this might be the only feasible means of providing for radio quietness to the desired extent, as for obvious safety reasons, it will be well-nigh impossible to curtail aircraft communications in the relevant area substantially enough to serve the purpose of the IRQZ. In as far as either applicable multilateral treaties ${ }^{8}$ or bilateral air services agreements provide for relevant obligations of the state(s) in question towards other states and their airlines and aircraft as to airways and transit rights, this would not even be allowed without further ado, since such international rights cannot be denied or abrogated unilaterally.

Here, the possibilities for 'time-sharing'-between overflying aircraft and radio astronomy observatories on the groundmight be further investigated. If, for example, the intervals between overflying aircraft leave enough time for such observatories to make useful observations, such time-sharing is de facto already realized at the outset, not even requiring for the time being any further regulatory measures.

\subsection{International Outer Space and International High Seas}

The major problem from an international legal perspective arises, where areas falling outside the legal control of any particular state are involved. By definition, in all cases relevant to IRQZs, this applies to the satellites which come within geographically relevant ranges of radio astronomy observatories on the ground, with the result of possible interference, and the requirement arises legally to prevent, to condition a prior and/ or control a posteriori activities of these satellites. Wherever any precise borderline between airspace and outer space may be considered to exist, ${ }^{9}$ it is beyond discussion that such satellites operate in outer space and, in consequence, are not subject to any (underlying) state's sovereign territorial jurisdiction. ${ }^{10}$ The LEO- and MEO-systems referred to, for example, operate at

${ }^{7}$ Cf. also Art. 9, Convention on International Civil Aviation (hereafter Chicago Convention), Chicago, done December 7, 1944, entered into force April 4, 1947; 15 UNTS 296; TIAS 1591.

${ }^{8}$ Cf. e.g. Artt. 1, 5, 6, Chicago Convention.

${ }^{9}$ See for this discussion e.g. literature mentioned in the present author's Private Enterprise and Public Interest in the European 'Spacescape' (1998), 12, at no. 17. To the extent such claims are put forward, they tend to envisage such a borderline at roughly some $100 \mathrm{~km}$ vertically above the earth.

${ }^{10}$ See Art. II, Outer Space Treaty. heights of at least a few hundred kilometers above the surface of the earth.

This leaves basically two ways of subjecting a particular mobile communications satellite to relevant obligations, for example, shutting down transmitters when overflying the IRQZ during certain periods. (It is taken to be self-evident that, contrary to aircraft, it will not be feasible even in principle to make individual satellites change course for the mere purpose of avoiding the upper part of an IRQZ.)

The first option is that of registration of the satellite, which gives the state of registration jurisdiction over it. ${ }^{11}$ However, obviously, this is a piecemeal and ad hoc measure, only applicable, moreover, to a state's 'own' satellites, i.e. satellites with respect to which the particular state(s) establishing the IRQZ qualify/ies as 'launching state'. ${ }^{12}$ A state simply cannot assert jurisdiction over a satellite through registration of it against the will of the (other) states involved in the launch of that particular satellite.

The other option consists of international treaty instruments, i.e. regulation on the international plane by the community of states as a whole. Here, the ITU legal framework immediately comes to mind, based on a Constitution, a Convention and Radio Regulations which have the status of treaty law. ${ }^{13}$ Relevant law has arisen within the ITU framework concerns, for example the reservation, exclusively or on a priority basis, of certain frequency bands for radio astronomy, ${ }^{14}$ and duties related to the avoidance of harmful interference with (other) ITU-coordinated communication activities (which include for this purpose the activities of merely receiving radio signals). ${ }^{15}$

Observatories which form the center of an IRQZ may also be constructed on islands in the high seas. In such cases, while the islands themselves and their territorial waters form part of sovereign territory in a legal sense, parts of the high seasqualifying as areas falling outside the territory of any particular state-will also become involved. The advantages of an

\footnotetext{
${ }^{11}$ See Art. VIII, Outer Space Treaty.

${ }^{12}$ See e.g. Art. II, Convention on Registration of Objects Launched into Outer Space, New York, adopted November 12, 1974, opened for signature January 14, 1975, entered into force September 15, 1976; 14 ILM 43 (1975); 28 UST 695; TIAS 8480; 1023 UNTS 15.

${ }^{13}$ Constitution and Convention of the International Telecommunication Union (hereafter ITU Constitution respectively ITU Convention), Geneva, done December 22, 1992, entered into force July 1, 1994; Final Acts of the Additional Plenipotentiary Conference, Geneva, 1992 (1993), at 1 and 71, respectively; Instrument amending the Constitution and Convention of the International Telecommunication Union (Geneva, 1992), Kyoto, done October 14, 1994, entered into force January 1, 1996; Final Acts of the Plenipotentiary Conference, Kyoto, 1994 (1995), at 1 and 23, respectively. The Plenipotentiary Conference at Minneapolis in 1998 further amended these instruments.

${ }^{14}$ Cf. e.g. Artt. 6, 12-14, ITU Constitution; Artt. 7-10, ITU Convention.

${ }^{15}$ Cf. e.g. Artt. 6, 44, 45, ITU Constitution.
} 
IRQZ largely covering sea or ocean areas are obvious. The need to allow for some safety-and distress-related seaborne or airborne communications in that IRQZ would remain, but would in all probability cause considerably less frequent interference in practice than in territory-bound circumstances.

Still, on the high seas, similar to outer space, the traditional freedoms of the high seas apply for all states and may not be curtailed by any particular state at its discretion. ${ }^{16}$ Some of these freedoms evidently involve communications issues, making it impossible for any single state to curtail such communications by means of an IRQZ without further ado.

\section{IRQZs: Potential Precedents under International Law}

Interestingly, international law already offers a number of legal constructions, which may serve as interesting potential precedents for the establishment of IRQZs.

\subsection{The Exclusive Economic Zone (EEZ)}

The concept of the EEZ was established by means of the 1982 Convention on the Law of the Sea, ${ }^{17}$ and concerns a zone with a maximum of 200 nautical miles of breadth (horizontally), calculated from the low-tide coast line and to be expressly announced by the coast state. The part of the EEZ closest to the shore forms part of the territorial waters of the relevant coast state anyway, and thus falls comprehensively under its jurisdiction; it does not require consideration here. The maximum breadth of the territorial waters allowed under the 1982 Convention is 12 nautical miles; so at least 188 nautical miles of an EEZ would fall outside coastal state territorial jurisdiction.

Abrogation of the traditional freedoms of the high seas - as mentioned, an area in legal terms largely comparable to that of outer space-in the EEZ constitutes the core element of the EEZ regime. This is, by way of exception to the rule, and only to the extent that the regime itself explicitly allows for the exercise of functional jurisdiction of the coastal state to the exclusion of others, for limited purposesFnotably regarding economic exploitation.

\footnotetext{
${ }^{16}$ These freedoms currently encompass the freedoms of navigation, of overflight, of laying submarine cables and pipelines, of constructing artificial islands and other installations, of fishing and of scientific research, with a few caveats; see Art. 87(1), United Nations Convention on the Law of the Sea, Montego Bay, adopted April 30, 1982, opened for signature December 10,1982, entered into force November 16, 1994; 21 ILM 1261 (1982).

${ }^{17}$ See in particular Part V, Artt. 55 ff., United Nations Convention on the Law of the Sea.
}

It could be envisaged by way of a three-dimensional analogy with EEZs to establish IRQZs sufficiently large in dimension, giving 'underlying' states functional jurisdiction for the specified and limited purpose of allowing certain radio astronomy observatories on their territory to operate without prohibitive interference. This would be in conformity with existing space law concepts and principles, and partly even in further elaboration thereof, and would result in the imposition of radio quietness to the desired extent on any communication satellite entering the IRQZ.

This could be labelled the 'EEZ-approach' to IRQZs: working towards an international agreement of sufficient substance and legal binding force to allow certain states to exercise welldefined and limited functional competencies in an IRQZ by way of an extension of their respective territorial sovereignties.

\subsection{Antarctica}

Antarctica presents another interesting case, especially, since as of 1998 the continent has been declared a "natural reserve dedicated to peace and science." Territorial claims, and indeed the possibility of asserting territorial claims with regard to this continent, widely considered to be terra communis (i.e. not susceptible to becoming part of any particular state's territory), were frozen by means of the Antarctic Treaty of $1959 .{ }^{18}$ This treaty involved as contracting parties all states having shown substantial interest in the continent, and this fact was given even greater importance with the later accession of other states once these had shown similar substantial interest.

As a consequence, the Antarctic Treaty has often been characterised as an optimal example of a 'law-making treaty'. While normally a treaty can only bind those states party to it, a lawmaking treaty would result in binding obligations at least as to its general contents also for those states not having ratified or even signed such a treaty. Antarctica is an area which perforce requires an 'all(-states)-or-nothing' approach; any meaningful preservation of certain general interests necessitates adherence by all states to relevant rules and principles. Only those states having undertaken substantial activities with regard to that continent, and having spent considerable efforts in terms of manpower and funds, are justified in claiming they can identify such general interests and take the appropriate legal measures. The burden of proof would rest squarely upon other states to show that such measures are not adequate or are

\footnotetext{
${ }^{18}$ Antarctic Treaty, Washington, done December 1, 1959, entered into force June 23, 1961; 402 UNTS 71. See esp. Art. IV.
} 
unjustified, before they could claim that such measures would not have to be respected and adhered to by them.

The Madrid Protocol entering into force in $1998^{19}$ was the culmination of a series of international initiatives progressively intending to preserve the environmentally pristine character of the continent. In this process, the balance between environmental and scientific concerns and prospective commercial interests shifted considerably to the benefit of the former. By declaring Antarctica a natural reserve for peace and science, the Protocol achieved a remarkable result: for a period of (at least) 50 years any economic exploitation (whether state or private) of Antarctic mineral resources is now prohibited in the interests of mankind, among those interests specifically being the advancement of science.

The Outer Space Treaty shows a number of characteristics rather similar to the Antarctic Treaty which may be of interest for the establishment of IRQZs. Obvious parallels seem to offer themselves with the interests of mankind as a whole in space science and investigation, and the desirability - in the abstract- to allow for some space for such activities in those areas where commercial interests would be, relatively speaking, little harmed by being conditioned.

This could be labelled the 'Antarctica-approach' to IRQZs: establishing by means of an international agreement of sufficient substance and legal binding force certain zones within the terra communis of outer space where all states are to refrain themselves, and restrain their entities, from undertaking any activities unduly interfering with the relevant radio astronomy activities.

\subsection{Denuclearized and/or Demilitarized Zones}

A more general case of interest for the present issue concerns the establishment of denuclearized and/or demilitarized zones. The general idea behind it obviously is that mankind is better off, i.e. runs fewer risks of nuclear or military escalation, if certain areas of the world remain free from nuclear or all weaponry-not just free from its use or its being tested, but free from its presence altogether.

Antarctica, outer space and the high seas, areas falling outside any state's jurisdiction (albeit in the first case not unequivocally so), are all denuclearized or demilitarized. However, the measure of denuclearization and demilitarisation realized differs substantially. Antarctica is completely demilitarized in the sense that military operations of any kind are prohibited, and military personnel are only allowed as long as operating for

${ }^{19}$ Protocol on Environmental Protection to the Antarctic Treaty, Madrid, done October 4, 1991, entered into force January 14, 1998; 30 ILM 1455 (1991). scientific purposes and under the direction of scientists. Nuclear weapons are completely outlawed. For outer space, on the other hand, a dichotomy is realized: on the Moon and other celestial bodies exclusively peaceful activities are the only activities admitted, whereas the void of outer space itself is only legally safeguarded against the stationing of nuclear and other mass-destruction weapons-using space as a trajectory for nuclear weapons is not outlawed. As for the high seas, a relevant treaty was concluded in $1971^{20}$ denuclearizing the seabed, ocean floor and subsoil thereof.

Also within the other category of denuclearized and/or demilitarized territories, those falling under state sovereignty, a number of different cases could be distinguished. East Germany, only part of the united Germany, is denuclearized to the extent of, and as a consequence of, the status of Germany as such, and is only for a certain period not to be occupied by NATO forces, possibly carrying nuclear arms. This status is the consequence of international treaty obligations involving, apart from Germany itself, the four victor states of World War II. ${ }^{21}$ The Treaty of Tlatelolco denuclearizes Latin America as a continent, ${ }^{22}$ whereas the Treaty of Rarotonga achieves the same for the South Pacific area. ${ }^{23}$ Both treaties, in addition to involving South American and Southern Pacific states, respectively (try to), involve the nuclear powers as guarantors by means of additional protocols. An effort to establish a nuclearfree zone in Africa has not yet met with success. ${ }^{24}$

A final category concerns purely unilateral initiatives by particular states to denuclearize one's own territory; this usually results in problems only within collective defence organizations where other member states do not wish to disclose whether particular arms shipments include nuclear weapons or not. Examples are Denmark within NATO and Australia and New Zealand within ASEAN, notably vis-à-vis the US. Perhaps somewhat similar in nature are the unilateral neutrality declarations which have been enunciated e.g. by Sweden and Finland. In sum, in some cases, the establishment of

\footnotetext{
${ }^{20}$ Treaty on the Prohibition of the Emplacement of Nuclear Weapons and Other Weapons of Mass Destruction on the Seabed and the Ocean Floor and in the Subsoil thereof, London/Moscow/Washington, adopted December 7, 1970, opened for signature February 11, 1971, entered into force May 18, 1972; 10 ILM 145 (1971).

${ }^{21}$ Cf. Artt. 3, 5, Treaty on the Final Settlement With Respect to Germany, Moscow, done September 12, 1990, entered into force March 4, 1991; 29 ILM 1186 (1990).

${ }^{22}$ Treaty for the Prohibition of Nuclear Weapons in Latin America, Mexico City, done February 14, 1967, entered into force September 20, 1967; 6 ILM 521 (1967).

${ }^{23}$ South Pacific Nuclear Free Zone Treaty, Rarotonga, done August 6, 1985, entered into force December 11, 1986; 24 ILM 1440 (1985).

${ }^{24}$ An African Nuclear-Weapon-Free Zone Treaty (Treaty of Pelindaba) was established in 1996, but, far from having entered into force, has enjoyed only three ratifications so far.
} 
denuclearized and/or demilitarized zones is similar to the essentials of the 'Antarctica-approach'; other cases, however, are of a completely different nature. Thus, the relevant legal constructions have been effectuated in a number of different legal ways, and this makes it difficult to distinguish any clear guidance from the precedents concerned, other than that of involving 'third' states as 'guarantors' of non-interference with a localised regime-i.e. an IRQZ once established.

\subsection{The Rule-Making Powers of ICAO over the High Seas}

Finally, a specific legal construction of interest concerns the rule-making powers which the International Civil Aviation Organization (ICAO) exercises over the high seas for aviation purposes. ${ }^{25}$ Comparable perhaps to some extent to functional jurisdiction, only this time not of a state but of an international intergovernmental organization, for the overriding interest of mankind in safe and efficient international air transportation activities it has been possible to subject the traditional freedom of overflight over the high seas to a system of binding (traffic) rules. Included in this regime are certain aspects of aeronautical communications. ${ }^{26}$

The analogy with the ITU, exercising for somewhat similar purposes competence vis-à-vis one particular but prominent use of outer space, as an area legally similar to the high seas, suggests itself. Indeed, the ITU deals with the two physical 'assets' which are indispensable for satellite communications: orbits and frequencies. The ITU coordinates the use of orbital slots, as far as the geostationary orbit is concerned, and of the orbits themselves in the cases of other orbits. It also coordinates the frequencies to be used with respect to the satellite occupying a certain slot or orbit, the so-called up-link and downlink frequencies. For these reasons, it would evidently be useful, practical and even unavoidable to involve the ITU-mechanism in any effort to establish a regime calling for limits to, conditions on, or the altogether ceasing of satellite transmission activities over a certain area.

However, it should be realized that the ITU does not possess competence comparable to that of ICAO. It would be highly doubtful whether ITU can determine, independently from individual member states, binding legal rights and obligations of a sufficiently far-reaching and substantial nature, let alone enforce regulations vis-à-vis specific states and their private entities. Such competence would seem rather to rest with the collectivity of member states operating through World Radio Conferences (WRCs) and similar mechanisms which control

${ }^{25}$ Cf. Artt. 12, 37(c), 44(a), (d) and (h), 54(l), 90, Chicago Convention; in conjunction with Annex 2 to the Convention.

${ }^{26}$ See also Annex 10 to the Chicago Convention. the fundamental parameters for the Radio Regulations and other ITU regulations.

While hitherto the ITU system may have served well, as generally undisputed and accepted by all states, this might no longer be the case. With the advent of thoroughly commercial applications, many private entities have entered this field who are more 'aggressive' in their market behavior, not always aware of-let alone sympathetic to-non-commercial public interests, and at any rate one step removed from the legal regime established within the ITU, still fundamentally an intergovernmental organization. Partly as a consequence, in addition, some of the states concerned have shown a tendency to disregard the slow, cumbersome and often inefficient and/or erratic processes taking place within the ITU.

Nevertheless, there is no inherent reason why this situation should not change. This 'ICAO-approach' to IRQZs_- having an international organization endowed, by means of an international agreement of sufficient substance and legal binding force, with (quasi-)jurisdictional competencies for the terra communis-part of the IRQZ - might point to either establishing similar powers for ITU, or establishing them for another international organization-existing or to be established. A similar approach might, moreover, result from closer analysis of the role which the International Maritime Organization (IMO) plays with respect to maritime activities on the high seas.

\section{Conclusions: Towards IRQZs under International Law?}

If IRQZs are indeed to be established, following from the foregoing analysis, three different fields actually offer themselves for legal action: the national areas, the aspect of orbits and frequencies for the international areas, and the international areas of outer space and the high seas as such.

\subsection{The National Areas}

A few individual states would have to be convinced of the desirability and practicability of IRQZs, in order to take all the national legislative measures required. An IRQZ incorporating territory of more than one state obviously requires such measures from all of the states concerned.

Such measures would result in a three-dimensional area of sufficient size to be subjected to maximum levels of interference with the observatory as the center of a series of superimposing domes. These measures should then basically lead to the results that: (1) no sending stations should be allowed to operate in that area if exceeding the applicable imposed maxi$\mathrm{ma}$, as subject further to time-sharing or frequency-sharing arrangements and (2) no aircraft should be allowed to enter the IRQZ, since, even if their entry as such would not already be prohibitive for radio astronomy activities, for reasons of safety 
aircraft could never be obliged to shut down communications channels. Obviously, any choice over 'time-sharing' or 'frequency-sharing' would considerably mitigate the consequences for communication satellite operators as well as aircraft and their respective operators, and would therefore present a much more feasible and acceptable option.

In addition, the applicable national legal system will have to ascertain legal force for any such measures, subject to the adjudicative authority of its court system, and establish the necessary executive powers to monitor and enforce adherence to the obligations and duly punish offenders.

In the 'national area', thus, national action by individual states is called for, ultimately resulting in implementation of the IRQZ with respect to its territory and airspace. On the international level, actions in this regard will consequently remain confined to efforts to interest relevant states, and to try to add on to any national efforts towards establishment of an IRQZ such international legal actions are necessary in the two other areas.

\subsection{The International Areas-Orbits and Frequencies}

No territorial sovereignty of individual states applies to the satellites which, in passing through the upper portions of an IRQZ, are to be forced to cease or minimize transmissions for the duration of such transit, or at least for certain periods or on certain frequencies. At first glance, the ITU may seem to be best poised to deal with this international part of a radio quiet zone.

Decisions taken at the WRCs combined with the Radio Regulations result in a very elaborate regime distributing rights to use certain frequencies and/or orbits (or orbital slots in the case of the geostationary orbit), often under conditions and with important refinements or exceptions by way of the socalled 'footnotes'. These Radio Regulations and the related WRC decisions basically have the same status as the ITU Constitution and ITU Convention, and are therefore indeed of a binding-treaty nature. ${ }^{27}$ Whether through Convention or WRCs and Radio Regulations, or a combination of both, allowance should be made for particular IRQZs in terms of frequency- and orbit-allotments, to be further implemented through national assignment procedures. Obviously, here an 'ITU-approach' would be essential.

Nevertheless, the ITU has no independent authority, where such independent authority would be the best guarantee against non-transparent and incoherent IRQZ-related policies. It must be realized furthermore that the ITU, as an organization established for functional reasons and along functionalist lines, has dealt with the coordination and allotment of frequency bands-i.e. reserving certain frequency bands for certain services_rather than reserving certain geographical areas for certain services irrespective of which frequencies are used. ${ }^{28}$ Thus, its authority and main field of activity are almost orthogonal to the essential parameters involved in establishing an IRQZ. In consequence, for example, the ITU has no authority to license or preclude operations for a certain area, as the FCC has; it does not even have the authority to condition licensing by national authorities apart from the de facto and rather indirect implementation of WRC decisions and Radio Regulations on frequency aspects.

The relevance of the ITU-framework for arranging any IRQZ has thus been determined, and the proper place of any 'ITU approach' - availing oneself of the ITU framework to realize the establishment of IRQZs - in this respect outlined. Since the fundamental characteristics of any IRQZ present so many features new to ITU procedures and regulation (comprehensiveness, size, measure of detail of arrangements required, need for monitoring equipment and procedures, sanction issues, requirement of an 'all-or-nothing-approach'), a quantumleap is required for which the ITU-structure might not be sufficiently equipped without fundamental changes.

\subsection{The International Areas_-Outer Space and High Seas}

The similarity of the concept of the IRQZ especially to such concepts as the EEZ, the natural reserve for peace and science which is Antarctica, and the international regulatory powers given to the ICAO under the Chicago Convention with respect to the airspace over the high seas, has been noted. Following also from the restricted possibilities offered by the 'ITU approach', such similarities point in the following direction.

For the international areas involved--outer space and possibly the high seas - one way or another an international licensing-relevant structure should be realized. Whilst licensing as such remains an essentially national activity, IRQZs would require a fundamental legal authority on an international scale, to control the use of transmitters in those areas and thus to subject it to relevant conditions and this in a manner fundamentally similar to licensing as it is currently undertaken, for example, by the FCC for the US - only partially in implementation of

\footnotetext{
${ }^{28}$ Only at a secondary level, geographical limitations are being provided for, in the sense that certain allotments may be made for certain areas. Usually, however, these areas concern one or two continents comprehensively, rather than individual states - let alone only parts thereof.
} 
ITU regulations! - and backed up with the required legal adjudication and enforcement competence.

Ideally, a treaty should be established which recognizes the principle of IRQZs. Such a treaty should then either give the individual states concerned functional jurisdiction in that zone, even for the part of it which extends to outer space (the 'EEZapproach'), or give the states party to it competence to jointly impose radio quietness in the outer space-part of an IRQZ (the 'Antarctica-approach'), or provide an organization (already existing or to be established by the treaty) with the competence to impose radio quietness there (the 'ICAO-approach'), or possibly any combination of the foregoing.

Notably, it should direct the implementation at the national level of licensing regimes required for the purpose. From the current perspective, inclusion of those states internationally responsible and/or internationally liable for private satellite communications operators ${ }^{29}$ in the treaty-regime to be established would be essential. These states are directly and comprehensively involved in the licensing of such operations and the conditioning of their operations, and can thus give effect to their international accountabilities at the domestic level.

Such a treaty, or an organization given the necessary functions by it, should also direct, or liaise with ITU to implement measures through the latter's regulatory mechanisms directly relating to the use of any frequencies and orbits for satellites whenever and wherever these are transiting radio quiet zones. Similar directions or liaising activities should be provided for in respect of ICAO and IMO in regard to issues of airborne and seaborne communications.

While a treaty_or a protocol to the Outer Space Treatyratified by all relevant states from the perspective of satellite communications would represent the legal optimum, there are obvious (political) risks inherent in such an approach. General agreement of a sufficiently substantive nature may be hard to come by or even impossible, and other issues might cloud the discussions. Also, the timeframes for more or less globally accepted treaties are notoriously long.

Lesser mechanisms than treaties, which nevertheless would not be without legal effect and might in the end themselves lead to a treaty or protocol being established, involve the possibility of establishing United Nations Resolutions, preferably by consensus, or even unilateral declarations by individual states announcing establishment of a particular IRQZ and expressing the intention — at least politically — to aim for international respect thereof by other relevant states and their private entities.

It may be interesting to bear in mind that the legal concept of the continental shelf, which was rapidly accepted by many other states and later codified in conventions on the law of the sea, started its existence as a legal concept by means of a unilateral declaration of the US in 1948. Also, in a somewhat similar vein, it may be recalled that the Antarctic Treaty, originally established by a mere 12 states and often blasted for its semiexclusive claims to establish the legal regime for that area and impose it erga omnes, now enjoys a partisanship of more than 40 states, and de facto - though sometimes grudging - respect from most other states in addition.

In the end, various roads might lead to Rome for the purpose of effectuating IRQZs. Which legal mechanism will be chosen therefore is ultimately a policy and/or political issueFas much as depending upon certain technical-scientific requirements and feasibilities, most notably those relating to distances from observatories and acceptable power levels. One thing is clear though: if mankind wants to continue to be able to listen to celestial symphonies, legal action will have to be taken in the near future. 